\title{
Fosfitos no manejo da antracnose do jiló
}

\author{
Elizabeth Rodrigues Alexandre(1), Luciana Maria Herculano(2) Josenilda Maria da Silva(3) \\ e Sônia Maria Alves de Oliveira(1)
}

\begin{abstract}
(1)Universidade Federal Rural de Pernambuco (UFRPE), Departamento de Agronomia, Laboratório de Patologia Pós-Colheita, Avenida Dom Manoel de Medeiros, s/no, Dois Irmãos, CEP 52171-900 Recife, PE, Brasil. E-mail: beth.agrofito@hotmail.com, oliveirasonia55@yahoo.com.br (2)UFRPE, Departamento de Química, Laboratório de Cultura de Tecidos Vegetais, CEP 52171-900 Recife, PE, Brasil. E-mail: luherculano@hotmail.com ${ }^{(3)}$ Centro Regional de Ciências Nucleares, Avenida Prof. Luiz Freire, № 200, Cidade Universitária, CEP 50740-540 Recife, PE, Brasil. E-mail: nildajm@crcn.com.br
\end{abstract}

Resumo - O objetivo deste trabalho foi avaliar os efeitos de fosfitos sobre a antracnose (Colletotrichum tamarilloi) em jiló, na pós-colheita. O crescimento micelial e a produção e a germinação de conídios foram avaliados após a aplicação dos sais de fosfitos de $\mathrm{Ca}, \mathrm{K}, \mathrm{Mg}, \mathrm{Zn}$ e Cu , nas concentrações de $0,25,0,50,0,75$,

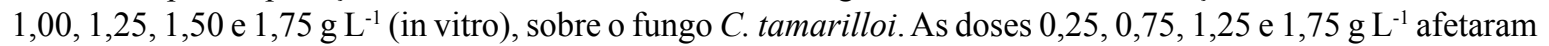
os frutos no período pós-colheita. Avaliaram-se os atributos químicos e a possível resposta bioquímica. A dose de $1,50 \mathrm{~g} \mathrm{~L}^{-1}$ foi utilizada no controle da antracnose, em pós-colheita, após inoculação do fungo. In vitro, a concentração efetiva para a redução de $50 \%$ do crescimento micelial e da produção e da germinação de conídios $\left(\mathrm{CE}_{50}\right)$ foi alcançada para as menores concentrações do fosfito de $\mathrm{K}$. Observou-se efeito linear quanto à redução da incidência da antracnose e ao aumento das atividades das enzimas oxidativas/reativas catalase, ascorbato peroxidase e polifenoloxidase. $\mathrm{O}$ fosfito de $\mathrm{K}$ foi o sal mais eficiente contra a antracnose, em frutos armazenados a $13 \pm 2^{\circ} \mathrm{C}$ e $24 \pm 2^{\circ} \mathrm{C}$, e tem potencial para ser utilizado para o manejo desta doença.

Termos para indexação: Colletotrichum tamarilloi, Solanum gilo, controle alternativo, patologia pós-colheita.

\section{Phosphites in the management of anthracnose on jilo}

\begin{abstract}
The objective of this work was to evaluate the effects of phosphites on anthracnose (Colletotrichum tamarilloi) on jilo at postharvest. Mycelial growth, and production and germination of conidia were evaluated after the application of $\mathrm{Ca}, \mathrm{K}, \mathrm{Mg}, \mathrm{Zn}$, and $\mathrm{Cu}$ phosphites at the doses of $0.25,0.50,0.75,1.00,1.25,1.50$, and $1.75 \mathrm{~g} \mathrm{~L}^{-1}$ (in vitro) on the fungus C. tamarilloi. The doses $0.25,0.75,1.25$, and $1.75 \mathrm{~g} \mathrm{~L}^{-1}$ affected fruit in the period postharvest. Chemical attributes and the possible biochemical response were evaluated. The dose of $1.50 \mathrm{~g} \mathrm{~L}^{-1}$ was used in the post-harvest management of anthracnose after fungus inoculation. In vitro, the effective concentration for $50 \%$ reduction of mycelial growth and of conidial production and germination $\left(\mathrm{EC}_{50}\right)$ was achieved for $\mathrm{K}$ phosphite lower concentrations. Linear effect was observed for the anthracnose incidence reduction and for the activity increase of oxidative/reactive catalase enzymes, ascorbate peroxidase, and polyphenoloxidase. Potassium phosphite was the most efficient salt against anthracnose, in stored fruit at $13 \pm 2^{\circ} \mathrm{C}$ and $24 \pm 2^{\circ} \mathrm{C}$, and it has the potential to be used for this disease management.
\end{abstract}

Index terms: Colletotrichum tamarilloi, Solanum gilo, alternative control, postharvest pathology.

\section{Introdução}

O jiló, Solanum gilo Raddi, é uma solanácea que tem origem e centro de diversidade na África, mas desde sua introdução foi amplamente distribuído e produzido no Brasil (Danquah \& Ofori, 2012; Pereira et al., 2012). O consumo do fruto, que tem um amargor peculiar, é justificado, pois esta hortaliça é um reservatório de nutrientes e fitoquímicos, entre os quais o ácido ascórbico, que apresenta valor nutricional e terapêutico (Mangan et al., 2008; Chinedu et al., 2011).

Hortaliça tropical e com reduzida vida útil, o que justifica a refrigeração como técnica de conservação mais adequada, a temperaturas de cerca de $13^{\circ} \mathrm{C}$ (Neres et al., 2004), o jiló é altamente suscetível à antracnose e a podridões causadas por Phytophthora spp. e Diaporthe vexans (Pereira et al., 2012). A antracnose por Colletotrichum spp. tem ampla gama de hospedeiros na família das solanáceas (Reis et al., 2009) e pode afetar $100 \%$ dos frutos. No gênero Solanum, algumas espécies estão relacionadas à antracnose e à podridão do fruto, como Colletotrichum acutatum J.H. Simmonds, C. gloeosporioides (Penz.) Penz \& Sacc. (Tozze Júnior et al., 2006) e espécies de C. acutatum senso lato como C. fioriniae (Marcelino \& Gouli) R.G. Shivas \& Y.P. Tan, C. godetiae Neerg., C. johnstonii 
Damm, P.F. Cannon \& Crous e C. tamarilloi Damm, P.F. Cannon \& Crous (Damm et al., 2012).

Ocontrole químico, com produtos à base de oxicloreto e sulfato de cobre, é a estratégia mais comumente usada no manejo da antracnose e outras doenças fúngicas do jiló no campo (Brasil, 2003), mas, em pós-colheita não foi localizado registro de nenhum composto ativo para controle da antracnose do jiló cultivado no Brasil. Uma alternativa é a utilização de fosfitos, sais inorgânicos, que são ânions $\left(\mathrm{P}_{2} \mathrm{O}_{5}\right)$ produzidos por neutralização do ácido fosforoso $\left(\mathrm{H}_{3} \mathrm{PO}_{3}{ }^{-}\right)$, em razão de seu efeito tóxico direto sobre fungos ou pela ativação das rotas de defesa da planta (Deliopoulus et al., 2010). Estes sais já vêm sendo utilizados na pós-colheita, combinados a outras estratégias de controle para culturas como citros e maçã, nas mais diversas formulações, principalmente o de fosfito de potássio (Blum et al., 2007; Cerioni et al., 2013).

O objetivo deste trabalho foi avaliar os efeitos de fosfitos sobre a antracnose em jiló, na pós-colheita.

\section{Material e Métodos}

Os experimentos foram realizados no Laboratório de Patologia Pós-Colheita, da Universidade Federal Rural de Pernambuco, Recife, PE, a 0800'59"S, $034^{\circ} 56^{\prime} 40^{\prime \prime} \mathrm{W}$, de maio a outubro de 2013 . Utilizouse um isolado representativo de Colletotrichum tamarilloi, oriundo de antracnose do fruto, para o ensaio de sensibilidade aos fosfitos. Para a avaliação in vitro quanto à sensibilidade, os fosfitos (Fosfitotal Intercurf, Campinas, SP, Brasil) de cálcio (Phi $\mathrm{Ca}$ $18 \%, 64 \% \mathrm{P}_{2} \mathrm{O}_{5}$ ), potássio ( $\mathrm{Phi} \mathrm{K} 38 \%, 58 \% \mathrm{P}_{2} \mathrm{O}_{5}$ ), magnésio (Phi $\mathrm{Mg} 11,5 \%, 74 \% \mathrm{P}_{2} \mathrm{O}_{5}$ ), zinco (Phi $\mathrm{Zn}$ $25 \%, 59 \% \mathrm{P}_{2} \mathrm{O}_{5}$ ) e cobre (Phi Cu 13\%, 31,5\% $\mathrm{P}_{2} \mathrm{O}_{5}$ ), nas concentrações $0,25,0,50,0,75,1,00,1,25,1,5 \mathrm{e}$ $1,75 \mathrm{~g} \mathrm{~L}^{-1}$ foram incorporados ao meio BDA, fundente a $45^{\circ} \mathrm{C}$, e vertidos em placas de Petri.

Para avaliação do efeito destes fosfitos sobre o C. tamarilloi, um disco de $3 \mathrm{~mm}$ diâmetro, com estruturas do fungo, foi depositado no centro de placas e incubado a $28^{\circ} \mathrm{C}$, em regime de luz contínua. $O$ fungo utilizado tinha cinco dias de cultivo em BDA. A testemunha constou do crescimento do fungo no meio BDA, em placa de Petri, sem adição de fosfito. Mensuraram-se os diâmetros ortogonais, tendo-se obtido a inibição do crescimento micelial (ICM) e, adicionalmente, a inibição da produção de conídios (IPC), por suspensão de conídios liberados em água destilada esterilizada (ADE). Utilizaram-se cinco placas/Phi/fungo. Paralelamente, verificou-se o efeito dos fosfitos sobre a germinação de conídios (IGER), nas mesmas concentrações anteriormente mencionadas. A suspensão foi de $10^{3} \mathrm{~mL}^{-1}$ conídios, ajustada em hemacitômetro, onde um volume de $30 \mu \mathrm{L}$ foi depositado em cavidades de lâmina escavada de oitos poços, para cada concentração de fosfito, neste mesmo volume. A testemunha constituiu-se da suspensão de conídios em ADE. A avaliação da germinação de conídios foi realizada por observação com $400 \mathrm{X}$ de aumento em microscópio óptico modelo N101-B (Coleman Equipamentos para Laboratório Com. e Imp. Ltda., Santo André, São Paulo), após oito horas em regime de luz contínua e paralisação com solução ácida de lactofenol. Considerou-se germinado o conídio independente do tamanho do tubo germinativo emitido. Para o cálculo do ICM, IPC e IGER, utilizou-se a relação (testemunha tratamento) / testemunha $\times 100$ (Latifa et al., 2011). A obtenção da concentração efetiva para a inibição de $50 \%\left(\mathrm{CE}_{50}\right)$ desses componentes avaliados foi determinada conforme Pereira et al. (2012), em todas as concentrações de fosfitos utilizadas. A comparação das médias pelo teste de Tukey, a 5\% de probabilidade, após a análise de variância, foi realizada pelo programa Statistix 9.0 (Tallahassee, Fl, USA).

No ensaio in vivo, utilizaram-se os cinco fosfitos (Phi), nas concentrações $0,25,0,75,1,25$ e $1,75 \mathrm{~g} \mathrm{~L}^{-1}$, que foram avaliados quanto à eficiência no controle da antracnose do jiló. Frutos imaturos de jiló 'Comprido Verde', com $16 \mathrm{~cm}$ de comprimento, provenientes do Município de Chã Grande (08 15'28"S, 35²9'24"W), $\mathrm{PE}$, foram obtidos de área com histórico da presença de antracnose. Esses frutos foram lavados em água corrente e sabão e desinfestados com hipoclorito de sódio a $1 \%$, durante três minutos. Os frutos foram tratados por imersão, por $20 \mathrm{~min}$, em recipientes de $8 \mathrm{~L}$ com a solução dos sais de fosfitos, em $\mathrm{pH} 4-5$ de solução final. A testemunha constou de jilós imersos em ADE. Em seguida, os jilós foram acondicionados em bandejas de poliestireno expandido, envolvidos em filme de plástico de PVC de $15 \mu \mathrm{m}$, submetidos às temperaturas de $24 \pm 2$ e $13 \pm 2{ }^{\circ} \mathrm{C}$ e mantidos em câmara fria por 20 dias. Realizaram-se avaliações da incidência de antracnose a cada cinco dias, no total de quatro avaliações, cujo valores em percentagem foram 
utilizados para a construção da área abaixo da curva de progresso da doença (AACPD), pela base matemática de Shaner \& Finney (1977). Após 20 dias, calculou-se a redução da incidência (\% controle) em comparação à testemunha.

$\mathrm{Na}$ avaliação dos atributos bioquímicos e de qualidade, utilizaram-se apenas as polpas dos jilós armazenados a $13 \pm 2^{\circ} \mathrm{C}$, obtidas das amostras após a retirada do pedicelo, que, depois foram trituradas em multiprocessador doméstico. A metodologia de Carvalho et al. (1990) foi utilizada para a determinação dos teores de ácido ascórbico (vitamina C). Para acidez titulável (AT), utilizou-se o método descrito em Helrich (1990). Os sólidos totais (ST) foram obtidos em $20 \mu \mathrm{L}$ do suco, depositados sobre o visor do refratômetro portátil Pocket PAL-1 0-53\% Brix (Atago Inc., WA, USA), e a determinação do $\mathrm{pH}$ foi obtido da polpa triturada, com leitura direta em potenciômetro Quimis Q-400A (Quimis Aparelhos Científicos Ltda., Diadema, SP).

As análises foram obtidas de três réplicas por amostra. Para a obtenção das análises de atividade das enzimas reativas de defesa, como ascorbato peroxidase (APX), catalase (CAT) e polifenoloxidase (PPO), 0,2 g do tecido retirado da região mediana do fruto, entre a casca e a polpa, foram macerados em nitrogênio liquido, homogeneizados a frio em tampão fosfato e polivinilpirrolidona e centrifugados a $10.000 \mathrm{~g}$ a $4^{\circ} \mathrm{C}$. Apenas o sobrenadante foi utilizado para o preparo do extrato.

A determinação da ascorbato peroxidase (APX, EC 1.11.1.11) foi feita em $225 \mu \mathrm{L}$ do extrato, de acordo com Koshiba (1993); a catalase (CAT, EC 1.11.1.6, em $150 \mu \mathrm{L}$ do extrato, conforme Beers Junior \& Sizer (1952); e a polifenoloxidase (PPO, EC 1.10.3.1), em $200 \mu \mathrm{L}$ do extrato, de acordo com Kar \& Mishra (1976). Determinou-se o teor de proteínas solúveis do extrato enzimático, que foi comparado a uma curva-padrão, para efeito dos cálculos das atividades enzimáticas (Bradford, 1976).

Em ambos os experimentos in vivo, utilizou-se o delineamento inteiramente casualizado, com arranjo fatorial $5 \times 4$ - cinco fosfitos e quatro concentrações -, com quatro repetições; a unidade amostral consistiu de quatro frutos, submetidos a duas condições de temperatura de armazenamento. Os dados da AACPD, atividades enzimáticas e análises químicas foram transformados em Log de $\mathrm{x}$, para atender à normalidade e análise de variância. Realizou-se a análise de regressão, e as equações foram ajustadas aos dados experimentais de cada fosfito empregado, a $5 \%$ de probabilidade. O teste de Dunnett, a $5 \%$ probabilidade, comparou a testemunha às concentrações dos fosfitos. Todos os experimentos foram realizados em duplicata, para a confirmação dos efeitos. As análises foram realizadas pelo programa Assistat, versão 7.6 beta (Silva \& Azevedo, 2009).

Em outro experimento, realizado nas mesmas condições de armazenamento já citadas, os frutos sem ferimentos foram inoculados artificialmente em laboratório, pela imersão em solução com concentração de $1 \times 10^{6}$ conídios $\mathrm{mL}^{-1}$ de $C$. tamarilloi, adaptado da metodologia de Blum et al. (2007). Após, os frutos receberam os tratamentos pela imersãos nas soluções com os fosfitos Phi Ca, Phi K, Phi Mg, Phi Zn e Phi $\mathrm{Cu}$ à dose de $1,50 \mathrm{~g} \mathrm{~L}^{-1}$, e com o fungicida oxicloreto de cobre como controle positivo à dose de $2,2 \mathrm{~g} \mathrm{~L}^{-1}$ i.a. A testemunha constituiu-se de jilós imersos em ADE. Foram avaliados: a incidência de antracnose $\left(I_{\text {máx }}\right)$, aos 20 dias após tratamentos; a redução da incidência da antracnose (\% controle); e, com o resultado das avaliações de incidência, foi calculada a área abaixo da curva de progresso da doença (AACPD). $\mathrm{O}$ experimento foi conduzido em delineamento inteiramente casualizado, com quatro repetições, e a unidade amostral foi constituida por quatro frutos. Os dados obtidos pela $I_{\text {máx }}$ AACPD e redução da incidência (\% controle) foram submetidos à análise de variância, seguida de comparação das médias pelo teste de Tukey, a 5\% de probabilidade, pelo programa Assistat versão 7.6 beta (Silva \& Azevedo, 2009).

\section{Resultados e Discussão}

Houve efeito dos fosfitos sobre C. tamarilloi em jiló (Tabela 1). Verificou-se que os fosfitos de $\mathrm{Zn}$ e $\mathrm{Cu}$ foram menos eficientes quanto à redução do crescimento micelial de C. tamarilloi, e os fosfitos de $\mathrm{K}, \mathrm{Ca}$ e $\mathrm{Mg}$ exerceram maior efeito sobre o fungo. Os fosfitos de $\mathrm{K}, \mathrm{Mg}$ e $\mathrm{Cu}$ não diferiram entre si, mas afetaram a germinação dos conídios do fungo, mesmo às menores concentrações. Ogoshi et al. (2013) observaram que o Phi $\mathrm{K}$ desempenhou atividade tóxica sobre C. gloeosporioides do cafeeiro (Coffea arabica L.) a concentrações de 5 e $10 \mathrm{~mL} \mathrm{~L}^{-1}$, com efeito direto sobre o fungo. O fungo C. gloeosporioides, 
responsável pela mancha foliar da 'Gala' em Malus domestica Bork., apresentou crescimento inibido em até $94 \%$, com o fosfito na formulação $40 \% \mathrm{P}_{2} \mathrm{O}_{2}, 20 \%$ $\mathrm{K}_{2} \mathrm{O}$ à concentração de $1,5 \mu \mathrm{L} \mathrm{mL}^{-1}$ (Araújo et al., 2010), o que indica o potencial do Phi K para interferir no desenvolvimento de $C$. tamarilloi. A inibição da germinação de $C$. gloeosporioides já foi mostrada por Shi et al. (2011), pela utilização do tetraborato de potássio $\left(\mathrm{K}_{2} \mathrm{~B}_{4} \mathrm{O}_{7} .4 \mathrm{H}_{2} \mathrm{O}\right)$ a $1,5 \mathrm{mmol} \mathrm{L}^{-1}$, o que ressaltou a possibilidade do uso deste sal para o controle da antracnose em manga (Mangifera indica L.). A $\mathrm{CE}_{50}$ pelo Phi K promoveu a menor produção de conídios de C. tamarilloi, entre todos os fosfitos utilizados no presente trabalho. Com esses resultados in vitro, foi possível verificar o potencial do uso de fosfito, com efeito tóxico direto, principalmente o Phi K, no controle de C. tamarilloi em jiló. Isto mostra a possibilidade do uso dos fosfitos no manejo da antracnose e corrobora os resultados de Mills et al. (2004), que mencionaram a utilidade destes sais na redução de podridões em frutos.

As concentrações dos fosfitos exerceram efeito sobre a AACPD quanto à antracnose, no armazenamento a $13 \pm 2^{\circ} \mathrm{C}$ e $24 \pm 2^{\circ} \mathrm{C}$ em comparação à testemunha (Tabela 2). Aos 10 dias de avaliação, a $24 \pm 2^{\circ} \mathrm{C}$, o jiló, que é climatérico e tem maturação irregular (Chitarra \& Chitarra, 2005), já apresentava sintoma típico de antracnose. Em termos comerciais, quando esta sintomalogia se manifesta, já inviabiliza os frutos. Para a conservação do fruto, sem comprometer a aparência externa, a temperatura de $13 \pm 2^{\circ} \mathrm{C}$ foi considerada

Tabela 1. Inibição de $50 \%\left(\mathrm{CE}_{50}\right)$ do crescimento micelial e da produção e da germinação de conídios de Colletrotrichum tamarilloi, em razão do uso de fosfitos ${ }^{(1)}$.

\begin{tabular}{lccc}
\hline Fosfito & Crescimento micelial & Produção de conídios & Germinação \\
\hline \multirow{3}{*}{ Phi Ca } & $0,037 \mathrm{~b}$ & $\mathrm{CE}_{50}(\mathrm{~g}$ i.a fosfitos L-1 & \\
& $( \pm 0.01)$ & $0,548 \mathrm{a}$ & $1,08 \mathrm{a}$ \\
Phi K & $0,033 \mathrm{~b}$ & $( \pm 0.01)$ & $( \pm 0.01)$ \\
& $( \pm 0.02)$ & $0,011 \mathrm{c}$ & $0,59 \mathrm{c}$ \\
Phi Mg & $0,15 \mathrm{~b}$ & $( \pm 0.05)$ & $( \pm 0.09)$ \\
& $( \pm 0.01)$ & $0,056 \mathrm{~b}$ & $0,56 \mathrm{c}$ \\
Phi Zn & $0,52 \mathrm{a}$ & $( \pm 0.002)$ & $( \pm 0.01)$ \\
& $( \pm 0.01)$ & $0,068 \mathrm{~b}$ & $0,67 \mathrm{~b}$ \\
Phi Cu & $0,54 \mathrm{a}$ & $( \pm 0.01)$ & $( \pm 0.02)$ \\
& $( \pm 0.03)$ & $0,56 \mathrm{a}$ & $0,54 \mathrm{c}$ \\
& 22,7 & $( \pm 0.009)$ & $( \pm 0.01)$ \\
\hline $\mathrm{CV}(\%)$ & & 8,27 & 22,7
\end{tabular}

${ }^{(1)}$ Médias seguidas de letras iguais, nas colunas, não diferem, pelo teste de Tukey, a $5 \%$ de probabilidade. Fosfitos (Phi): Ca (cálcio), $\mathrm{K}$ (potássio), $\mathrm{Mg}$ (magnésio), $\mathrm{Zn}$ (zinco) e $\mathrm{Cu}$ (cobre). ideal, o que corrobora os dados de Neres et al. (2004). Assim, a associação da temperatura de conservação aos tratamentos com fosfitos possibilitou a manutenção da qualidade, aliada à promissora utilização de fosfitos no controle da antracnose do jiló.

Os fosfitos Phi Ca e Phi $\mathrm{Mg}$ não diferiram entre si, à temperatura ambiente de $24^{\circ} \mathrm{C}\left(\mathrm{F}_{\mathrm{Phi}=73,33} ; \mathrm{F}_{\mathrm{C}=144,90 ; \mathrm{p}<0,01}\right.$; $\left.\mathrm{F}_{\text {Int }=2,30 ; \mathrm{p}=0,016} ; \mathrm{F}_{\text {IxTes }=251,05 ; \mathrm{p}<0,001}\right)$. Nas concentrações mais elevadas, estes sais juntamente com o Phi K, mostraram comportamento similar na redução da AACPD para incidência da antracnose (Figura $1 \mathrm{~A}$ ). Sob refrigeração a $13^{\circ} \mathrm{C}\left(\mathrm{F}_{\mathrm{Phi}=6,24} ; \mathrm{F}_{\mathrm{C}=56,33} ; \mathrm{F}_{\text {Int }=4,91} ; \mathrm{F}_{\text {IxTes }=71,7 ; \mathrm{p}<0,001}\right)$, o Phi $\mathrm{K}$, nas concentrações 1,25 e $1,75 \mathrm{~g} \mathrm{~L}^{-1}$, mostrou efeito mais pronunciado sobre a redução da AACPD da incidência da antracnose (Figura $2 \mathrm{~B}$ ). Assim, o Phi K foi o que resultou no melhor controle $\left(24 \pm 2^{\circ} \mathrm{C}=\mathrm{F}_{\mathrm{Phi}}=94,32\right.$; $\mathrm{F}_{\mathrm{C}=277,0} ; \quad \mathrm{F}_{\text {Int }=12,13 ; \mathrm{p}<0,001} \quad$ e $13 \pm 2 \quad{ }^{\circ} \mathrm{C}=\mathrm{F}_{\mathrm{Phi}=114,6} ; \quad \mathrm{F}_{\mathrm{C}=125,7} ;$ $\mathrm{F}_{\text {Int }=5,56 ; \mathrm{p}<0,001}$ ) (Figura $2 \mathrm{~A}$ e B), na pós-colheita, durante o armazenamento dos frutos, com inibição expressiva da antracnose oriunda de infecções quiescentes vindas

Tabela 2. Concentrações de fosfitos sobre a atividade das enzimas reativas e oxidativas, e na área abaixo da curva de incidência da antracnose (AACPD) do jiló, em comparação ao tratamento-controle (Phi-).

\begin{tabular}{|c|c|c|c|c|c|c|}
\hline Fosfito $^{(1)}$ & Catalase & $\begin{array}{l}\text { Ascorbato } \\
\text { peroxidase }\end{array}$ & $\begin{array}{c}\text { Polifeno- } \\
\text { loxidase }\end{array}$ & $\begin{array}{c}\text { Ácido } \\
\text { ascórbico }\end{array}$ & $\begin{array}{c}\text { AACPD } \\
24^{\circ} \mathrm{C} \\
\end{array}$ & $\begin{array}{c}\text { AACPD } \\
13^{\circ} \mathrm{C} \\
\end{array}$ \\
\hline Phi Ca c1 & & $*$ & $*$ & & & $*$ \\
\hline $\mathrm{Phi} \mathrm{Ca}$ c2 & & & & & & $*$ \\
\hline Phi Ca c3 & & & $*$ & & & $*$ \\
\hline Phi Ca c4 & & $*$ & & $*$ & & $*$ \\
\hline Phi K c1 & $*$ & $*$ & $*$ & & & $*$ \\
\hline Phi K c2 & & $*$ & $*$ & $*$ & & $*$ \\
\hline Phi K c3 & & $*$ & & $*$ & & $*$ \\
\hline Phi K c4 & & $*$ & & $*$ & & $*$ \\
\hline Phi Mg c1 & $*$ & $*$ & $*$ & & & $*$ \\
\hline Phi Mg c2 & $*$ & $*$ & $*$ & $*$ & $*$ & \\
\hline Phi Mg c3 & & $*$ & & $*$ & $*$ & \\
\hline Phi Mg c4 & & $*$ & & $*$ & $*$ & \\
\hline Phi Zn c1 & $*$ & $*$ & $*$ & $*$ & $*$ & $*$ \\
\hline Phi Zn c2 & & $*$ & $*$ & $*$ & $*$ & \\
\hline Phi Zn c3 & & $*$ & & $*$ & $*$ & \\
\hline Phi Zn c4 & & $*$ & & $*$ & $*$ & \\
\hline Phi Cu c1 & $*$ & $*$ & $*$ & & & $*$ \\
\hline Phi Cu c2 & & $*$ & $*$ & $*$ & $*$ & \\
\hline Phi Cu c3 & & $*$ & & $*$ & $*$ & \\
\hline Phi Cu c4 & & & & $*$ & $*$ & \\
\hline Phi - & \# & \# & $\#$ & \# & \# & \# \\
\hline
\end{tabular}

Pesq. agropec. bras., Brasília, v.49, n.12, p.930-938, dez. 2014 DOI: 10.1590/S0100-204X2014001200003 
do campo. Blum et al. (2007) também observaram redução da incidência do mofo-azul (Penicillium expansum Link.) em maçã (Malus domestica Borkh.), pelo efeito de Phi $\mathrm{K}$ em doses entre $0,75-1,5 \mathrm{~mL} \mathrm{~L}^{-1}$.

O Phi K conferiu proteção de $85-90$ \% na redução da antracnose nos frutos, em ambas as condições de armazenamento, contra o desenvolvimento de lesões oriundas de infecções quiescentes. O K pode atuar em processos enzimáticos e na preservação da integridade, que poderão contribuir para formação de frutos mais resistentes a podridões (Chitarra \& Chitarra, 2005). Amiri \& Bompeix (2011) também verificaram que o sal de $\mathrm{K}\left(2 \mathrm{mg} \mathrm{mL}^{-1}\right)$ preveniu o desenvolvimento do mofo-azul em maçã 'Elstar' durante o armazenamento.

A eficiência dos fosfitos a $1,50 \mathrm{~g} \mathrm{~L}^{-1}$ (dose de campo) contra o desenvolvimento da antracnose só foi
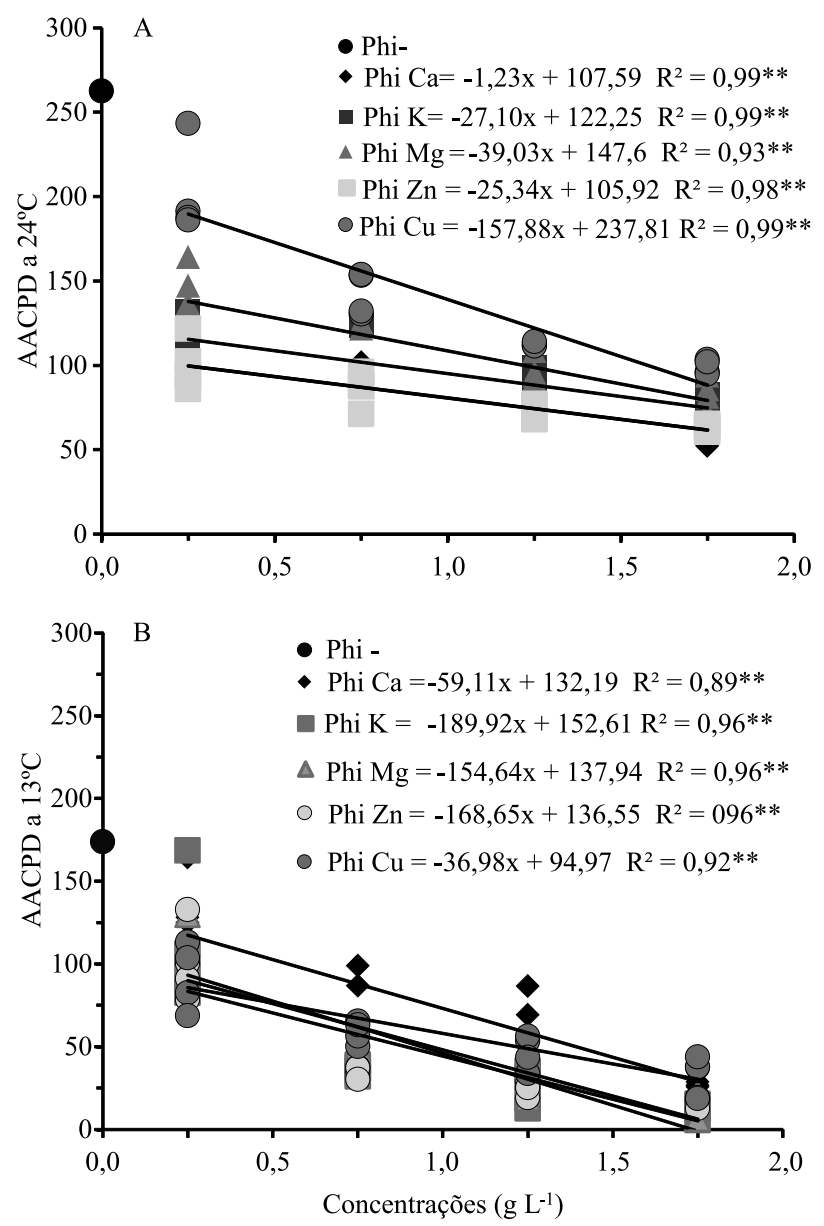

Figura 1. Área abaixo da curva de progresso da incidência da antracnose (AACPD), em jiló, após tratamento com fosfitos seguido de armazenamento a $24 \pm 2^{\circ} \mathrm{C}$ (A) e $13 \pm 2^{\circ} \mathrm{C}$ (B). **Significativo a $1 \%$ de probabilidade. verificada nos fosfitos de $\mathrm{Ke} \mathrm{Zn}$ a $24 \pm 2{ }^{\circ} \mathrm{C}$, com redução da incidência em 36,28 e $22,96 \%$, respectivamente, no progresso da incidência e, também, na $\mathrm{I}_{\text {máx }}$ (Tabela 3 ). A $13 \pm 2^{\circ} \mathrm{C}$, além destes sais, o Phi Ca reduziu a $\mathrm{I}_{\text {máx }}$ e a AACPD, e causou 5,03\% (Phi Ca), 35,85\% (Phi $\mathrm{K}), 33,05 \%$ (Phi Zn) de inibição ao desenvolvimento de C. tamarilloi. Estes fosfitos, principalmente o Phi $\mathrm{K}$, foram eficientes no manejo da antracnose em pós-colheita (Tabela 3).

Os atributos de qualidade $\mathrm{pH} \quad\left(\mathrm{F}_{\mathrm{Phi}=0,59 ; \mathrm{p}>0,05}\right.$; $\left.\mathrm{F}_{\mathrm{C}=1,68 ; \mathrm{p}=0,17} ; \mathrm{F}_{\mathrm{Int}=1,02 ; \mathrm{p}=0,43} ; \mathrm{F}_{\mathrm{IxTes}=0,05 ; \mathrm{p}>0,05}\right)$ e Brix $^{\circ}\left(\mathrm{F}_{\mathrm{Phi}=0,68}\right.$; $\left.\mathrm{F}_{\mathrm{C}=0,16 ; \mathrm{p}>0,05} ; \quad \mathrm{F}_{\text {Int }=1,50 ; \mathrm{p}=0,14} ; \quad \mathrm{F}_{\text {IxTes=0,17;p>0,05}}\right)$ não foram alterados e apresentaram teores de 4,75-4,81 e 5,795,88 , respectivamente. Para os valores de acidez total, observou-se uma faixa de 0,19 a 0,24 por $100 \mathrm{gde}$ ácido cítrico por polpa $\left(\mathrm{F}_{\mathrm{Phi}=3,73 ; \mathrm{p}=0,008} ; \mathrm{F}_{\mathrm{C}=2,75 ; \mathrm{p}=0,13} ; \mathrm{F}_{\mathrm{Int}=0,35 ; \mathrm{p}>0,005}\right.$;
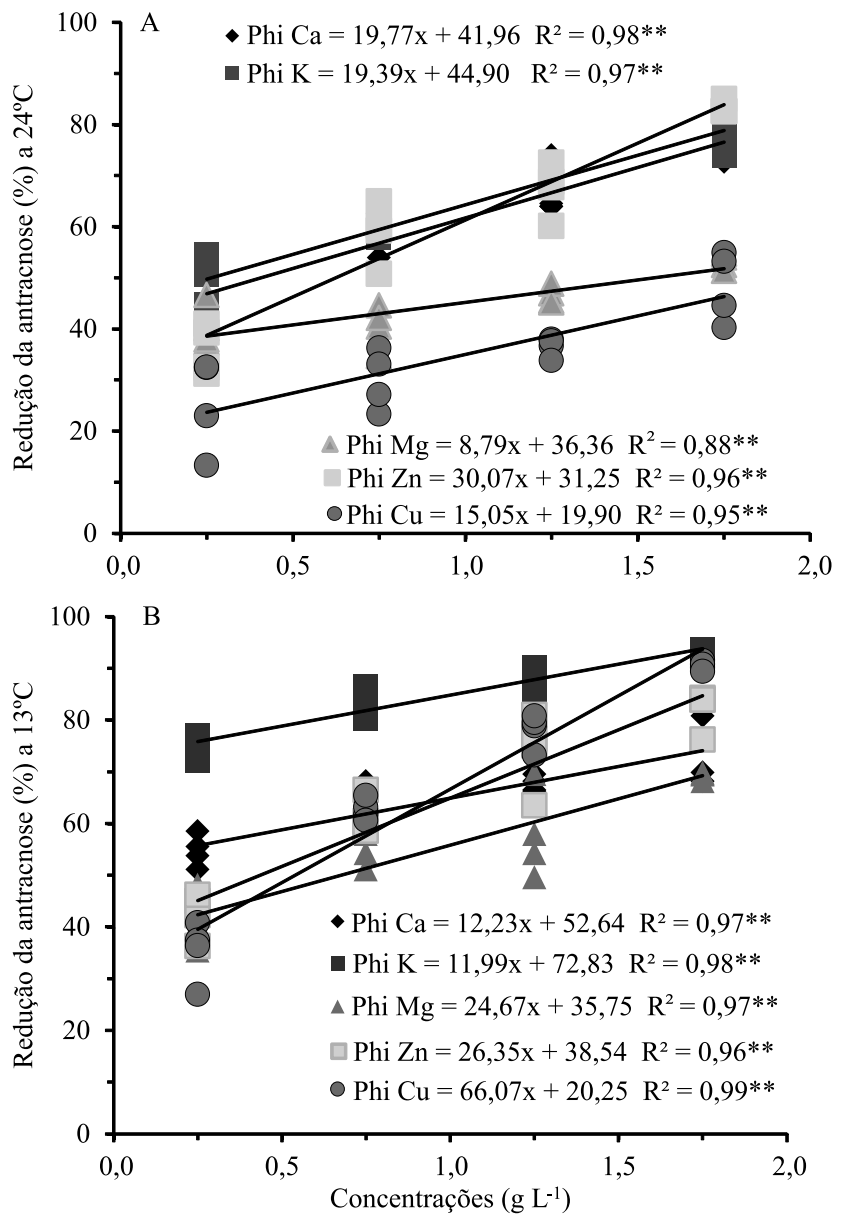

Figura 2. Redução (\%, controle) da incidência da antracnose em jiló, após tratamentos com fosfitos, em conservação a $24 \pm 2^{\circ} \mathrm{C}$ (A) e $13 \pm 2{ }^{\circ} \mathrm{C}$ (B). **Significativo a $1 \%$ de probabilidade. 


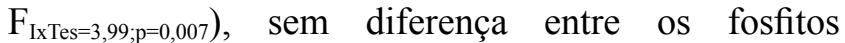
empregados. Stella et al. (2013) verificaram ausência de alteração nos teores dos SS, AT e outros atributos, como firmeza e textura, em maçãs 'Fuji' tratadas em pré-colheita com fosfito de $\mathrm{K}$, com manutenção da qualidade da fruta após a colheita. O teor de ácido ascórbico foi comprometido pelos Phi $\mathrm{K}$ e $\mathrm{Mg}$ nas maiores concentrações (Figura 3), com valores menores do que os $6,8 \mathrm{mg} 100 \mathrm{~g}^{-1}$ de polpa in natura, recomendados pelo Núcleo de Estudos e Pesquisas em Alimentação, da Universidade Estadual de Campinas (Tabela brasileira de composição de alimentos, 2011). Como o jiló pode ter múltiplas formas de consumo, o efeito desse atributo poderia ser superado por outros constituintes igualmente importantes, como vitaminas dos complexos A e B, e fitoquímicos (esteroides glicoalcaloides e flavonoides), que podem ter contribuição nutritiva e terapêutica (Joaquim et al., 2010; Chinedu et al., 2011)

Verificou-se efeito significativo da interação entre os fosfitos e as concentrações utilizadas para as enzimas catalase $\left(\mathrm{F}_{\mathrm{Phi}=8,73} ; \mathrm{F}_{\mathrm{C}=54,14 ; \mathrm{p}<0,001} \mathrm{~F}_{\mathrm{Int}=2,53 ; \mathrm{p}=0,013}\right.$; $\left.\mathrm{F}_{\text {IxTes }=6,47 ; \mathrm{p}=0,01}\right)$, ascorbato peroxidase $\left(\mathrm{F}_{\mathrm{Phi}=18,74} ; \mathrm{F}_{\mathrm{C}=50,03}\right.$; $\left.\mathrm{F}_{\mathrm{I}=2,85} ; \mathrm{F}_{\text {IxTes }=43,58 ; \mathrm{p}<0,001}\right)$ e polifenoloxidase $\left(\mathrm{F}_{\text {Phi=4,03; } \mathrm{p}=0,0074}\right.$; $\mathrm{F}_{\mathrm{C}=17,63 ; \mathrm{p}<0,001} ; \mathrm{F}_{\mathrm{I}=3,28 ; \mathrm{p}=0,0021} ; \mathrm{F}_{\mathrm{IxTes}=20,53 ; \mathrm{p}<0,001}$ ) (Tabela 2 e Figura 4). A maior atividade da enzima catalase verificada às menores concentrações do Phi K, pode ser atribuída à maior interação na tentativa de

Tabela 3. Efeito dos diferentes fosfitos sobre o fungo Colletotrichum tamarilloi, em jiló armazenado a duas temperaturas, em comparação ao efeito do fungicida oxicloreto de cobre ${ }^{(1)}$.

\begin{tabular}{lcccccccc}
\hline Fosfito $^{(2)}$ & \multicolumn{4}{c}{$24 \pm 2^{\circ} \mathrm{C}$} & & \multicolumn{3}{c}{$13 \pm 2^{\circ} \mathrm{C}$} \\
\cline { 2 - 5 } \cline { 7 - 8 } & AACPD & $\mathrm{I}_{\max }$ & Controle (\%) & & AACPD & $\mathrm{I}_{\max }$ & Controle (\%) \\
\hline Phi Ca & $143,9 \mathrm{~cd}$ & $36,6 \mathrm{bc}$ & 0,0 & & $88,4 \mathrm{bc}$ & $21,4 \mathrm{~b}$ & 5,0 \\
Phi K & $82,7 \mathrm{f}$ & $17,9 \mathrm{~d}$ & 36,3 & & $74,0 \mathrm{c}$ & $14,1 \mathrm{c}$ & 35,8 \\
Phi Mg & $179,8 \mathrm{bc}$ & $44,8 \mathrm{~b}$ & 0,0 & & $96,9 \mathrm{abc}$ & $25,9 \mathrm{ab}$ & 0,0 \\
Phi Zn & $101,5 \mathrm{ef}$ & $21,7 \mathrm{~cd}$ & 23,0 & & $74,1 \mathrm{c}$ & $14,2 \mathrm{c}$ & 33,0 \\
Phi Cu & $189,0 \mathrm{~b}$ & $43,4 \mathrm{~b}$ & 0,0 & & $100,0 \mathrm{ab}$ & $27,5 \mathrm{ab}$ & 0,0 \\
Phi - & $288,3 \mathrm{a}$ & $69,8 \mathrm{a}$ & 0,0 & & $123,9 \mathrm{a}$ & $33,3 \mathrm{a}$ & 0,0 \\
Fungicida $^{(3)}$ & $125,9 \mathrm{de}$ & $28,2 \mathrm{c}$ & - & & $89,1 \mathrm{abc}$ & $21,9 \mathrm{~b}$ & - \\
\hline
\end{tabular}

${ }^{(1)}$ Médias seguidas de letras iguais, nas colunas, não diferem entre si, a 5\% probabilidade, pelo teste de Tukey. ${ }^{(2)}$ Fosfitos: cálcio (Phi Ca), potássio (Phi $\mathrm{K})$, magnésio $(\mathrm{Phi} \mathrm{Mg})$, zinco $(\mathrm{Phi} \mathrm{Zn})$ e cobre $(\mathrm{Phi} \mathrm{Cu})$, à concentração de $1,50 \mathrm{~g} \mathrm{~L}^{-1} \cdot{ }^{(3)}$ Fungicida oxicloreto de cobre a 2,2 $\mathrm{g} \mathrm{L}^{-1}$ i.a. - não aplicável. Os valores das médias originais são mostrados de dados transformados em $\log$ de x. AACPD, área da curva abaixo do progresso da incidência da antracnose; $I_{\text {máx }}$, incidência máxima aos 20 dias. defesa à infecção pelo Colletotrichum. A enzima ascorbato peroxidase apresentou maior expressão após tratamentos com os Phi de $\mathrm{K}, \mathrm{Mg}, \mathrm{Zn}$ e Cu e menores concentrações com o Phi Ca.

Essas enzimas estão relacionadas à produção e remoção de espécies ativas de oxigênio como $\mathrm{H}_{2} \mathrm{O}_{2}$ e podem explicar o balanço da relação da infecção do fungo no tecido de frutos (Ballester et al., 2006). $\mathrm{O}$ acúmulo deste composto no fruto está relacionado à capacidade de colonização do fungo, com interferência no desenvolvimento do fitopatógeno (Anand et al., 2009). O aumento das enzimas catalase e ascorbato peroxidase, possivelmente, atuaram na redução do efeito de espécies ativas de oxigênio capazes de favorecerem o desenvolvimento do fungo, observado nas menores concentrações dos fosfitos. Nas maiores concentrações dos fosfitos, a redução dessas enzimas coincide com a menor incidência da antracnose nos frutos.

Com o incremento das concentrações dos fosfitos, valores elevados da enzima polifenoloxidase foram observados, com menor incidência de podridão do fruto pela antracnose. Lobato et al. (2011) também verificaram aumento de polifenoloxidase em batatas (Solanum tuberosum L.), obtidas a partir de plantas tratadas com Phi K e infectadas com Phytophthora infestans, além de redução dos sintomas de podridão causada por Pectobacterium carotovorum e Fusarium

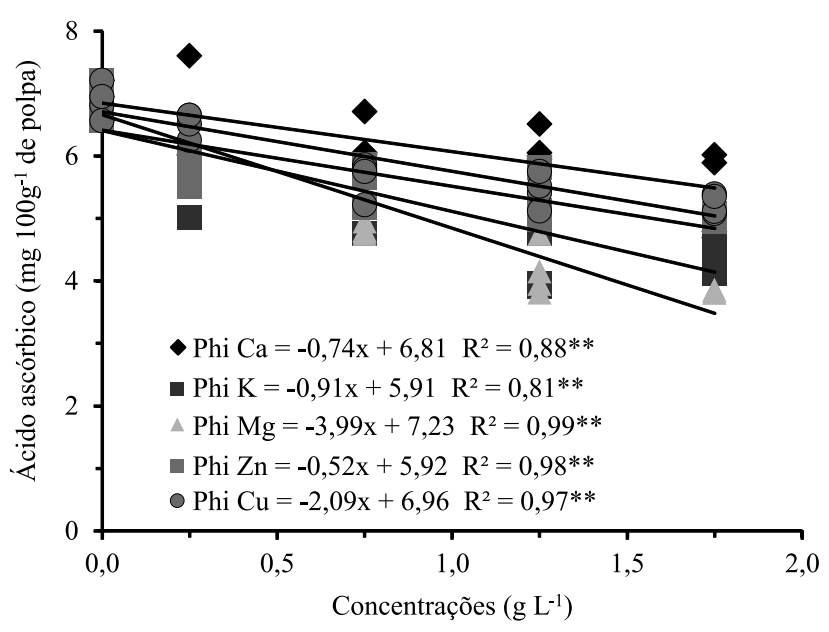

Figura 3. Efeito das concentrações dos fosfitos sobre o teor de ácido ascórbico (vitamina C) do jiló, após 20 dias de armazenamento a $13 \pm 2{ }^{\circ} \mathrm{C}$. ${ }^{*}$ Significativo a $1 \%$ de probabilidade.

Pesq. agropec. bras., Brasília, v.49, n.12, p.930-938, dez. 2014 DOI: $10.1590 / \mathrm{S} 0100-204 \mathrm{X} 2014001200003$ 

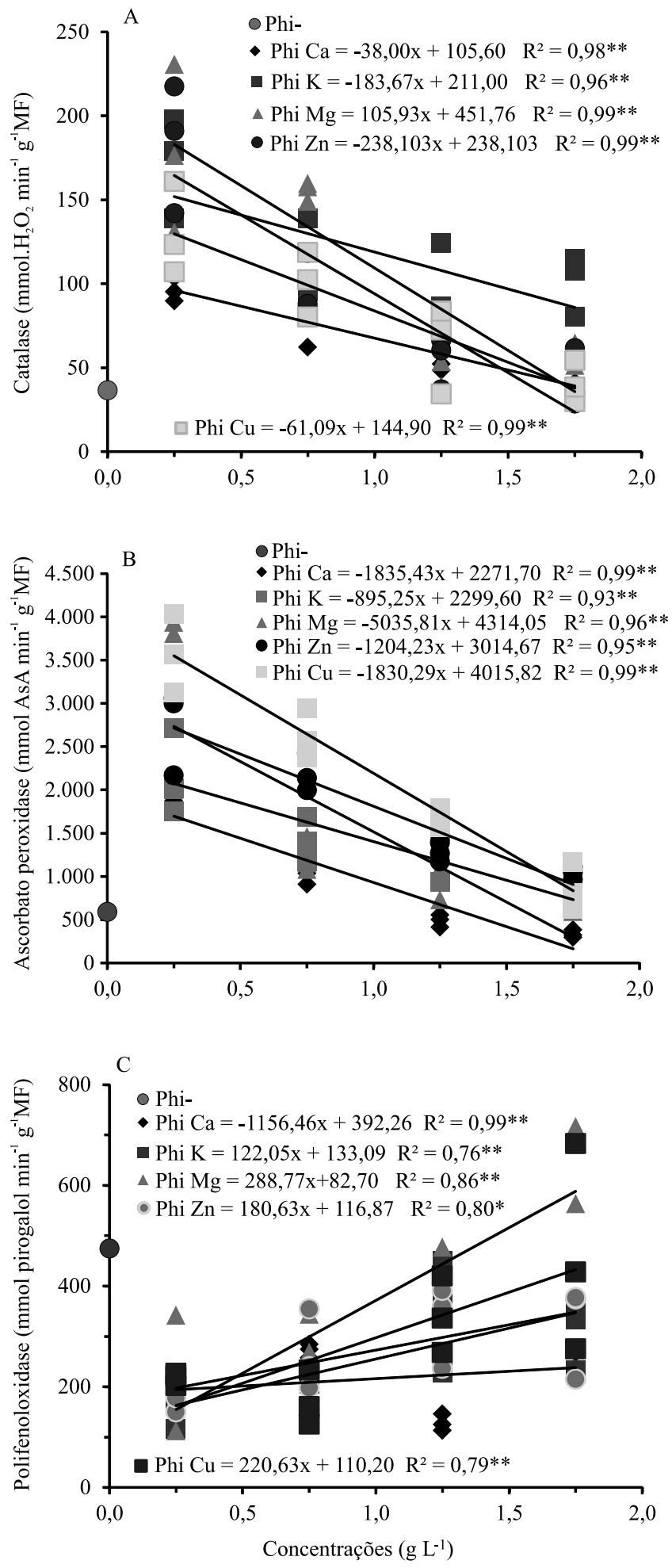

Figura 4. Interação do efeito das concentrações de fosfitos sobre as atividades das enzimas oxidativas e reativas catalase (A), ascorbato peroxidase (B) e polifenoloxidase (C), em polpa de jiló, após 20 dias do tratamento e armazenamento a $13 \pm 2{ }^{\circ} \mathrm{C}$. **Significativo a $1 \%$ de probabilidade. AsA, ascorbato reduzido. solani. Os resultados da expressão enzimática indicaram a promoção da interação fruto $\mathrm{x}$ fosfitos contra a infecção do $C$. tamarilloi, principalmente para o Phi K. O tecido do jiló que recebeu as maiores concentrações de fosfitos reagiu na presença destes, 0 que evitou o ataque do fungo pelo prolongamento da quiescência. Olivieri et al. (2012) também verificaram indução da atividade e a manifestação de defesa em batatas a patógenos, em razão do uso de Phi K.

A atuação dos fosfitos em pós-colheita indica $\mathrm{O}$ potencial de utilização destes sais, principalmente o Phi K, na redução da antracnose do jiló ainda em campo, após estudos que contemplem experimentos em pré-colheita.

\section{Conclusões}

1. O fosfito de $\mathrm{K}$ exerce efeito fungicida, in vitro, sobre Colletotrichum tamarilloi e nos frutos de jiló com infecções quiescentes de Colletotrichum.

2. Os fosfitos nas concentrações 1,25 e $1,75 \mathrm{~g} \mathrm{~L}^{-1}$ reduzem a incidência da antracnose e mantêm a qualidade de frutos de jiló armazenados a $13 \pm 2^{\circ} \mathrm{C}$.

3. O uso dos fosfitos em frutos de jiló aumenta a expressão das enzimas ascorbato peroxidase, catalase e polifenoloxidase contra o desenvolvimento da antracnose.

\section{Agradecimentos}

Ao Conselho Nacional de Desenvolvimento Científico e Tecnológico (CNPq), por bolsa concedida; e à Prof ${ }^{\mathrm{a}}$. Terezinha Câmara, do Departamento de Química, da Universidade Federal Rural de Pernambuco, pelo apoio na condução das análises enzimáticas.

\section{Referências}

AMIRI, A.; BOMPEIX, G. Control of Penicillium expansum with potassium phosphite and heat treatment. Crop Protection, v.30, p.222-227, 2011. DOI: 10.1016/j.cropro.2010.10.010.

ANAND, T.; BHASKARAN, R.; RAGUCHANDER, T.; SAMIYAPPAN, R.; PRAKASAM, V.; GOPALAKRISHNAN, C. Defence responses of chilli fruits to Colletotrichum capsici and Alternaria alternata. Biologia Plantarum, v.53, p.553-559, 2009. DOI: 10.1007/s10535-009-0100-5.

ARAÚJO, L.; VALDEBENITO-SANHUEZA, R.M.; STADNIK, M.J. Avaliação de formulações de fosfito de potássio sobre Colletotrichum gloeosporioides in vitro e no controle 
pós-infeccional da mancha foliar de Glomerella em macieira. Tropical Plant Pathology, v.35, p.54-59, 2010.

BALLESTER, A.R.; LAFUENTE, M.T.; GONZÁLEZ-CANDELAS, L. Spatial study of antioxidant enzymes, peroxidase and phenylalanine ammonia-lyase in the citrus fruit-Penicillium digitatum interaction. Postharvest Biology and Technology, v.39, p.115-124, 2006. DOI: 10.1016/j. postharvbio.2005.10.002.

BEERS JUNIOR, R.F.; SIZER, I.W. A spectrophotometric method for measuring the breakdown of hydrogen peroxide by catalase. The Journal of Biological Chemistry, v.195, p.133-140, 1952.

BLUM, L.E.B.; AMARANTE, C.V.T. do; DEZANET, A.; LIMA, E.B. de; HACK NETO, H.; ÁVILA, R.D.; SIEGA, V. Fosfitos aplicados em pós-colheita reduzem o mofo-azul em maçãs 'Fuji' e 'Gala'. Revista Brasileira de Fruticultura, v.29, p.265-268, 2007. DOI: $10.1590 / \mathrm{S} 0100-29452007000200015$.

BRADFORD, M.M. A rapid and sensitive method for the quantitation of microgram quantities of protein utilizing the principle of protein-dye binding. Analytical Biochemistry, v.72, p.248-254, 1976. DOI: 10.1016/0003-2697(76)90527-3.

BRASIL. Ministério da Agricultura, Pecuária e Abastecimento. AGROFIT: consulta de produtos formulados. 2003. Disponível em: <http://agrofit.agricultura.gov.br/agrofit_cons/principal_ agrofit_cons>. Acesso em: 14 fev. 2014.

CARVALHO, C.R.L.; MANTOVANI, D.M.; CARVALHO, P.R.N.; MORAIS, R.M. Análise química de alimentos. Campinas: ITAL, 1990. 115p.

CERIONI, L.; RAPISARDA, V.A.; DOCTOR, J.; FIKKERT, S.; RUIZ, T.; FASSEL, R.; SMILANICK, J.L. Use of phosphite salts in laboratory and semicommercial tests to control citrus postharvest decay. Plant Disease, v.97, p.201-212, 2013. DOI: 10.1094/ PDIS-03-12-0299-RE.

CHINEDU, S.N.; OLASUMBO, A.C.; OKWUCHUKWU, K.E.; EMILOJU, O.E.; OLAJUMOKE, K.A.; DANIA, D.I. Proximate and phytochemical analyses of Solanum aethiopicum L. and Solanum macrocarpon L. fruits. Research Journal of Chemical Sciences, v.1, p.63-71, 2011.

CHITARRA, M.I.F.; CHITARRA, A.B. Pós-colheita de frutos e hortaliças: fisiologia e manuseio. 2.ed. Lavras: UFLA, 2005. 785p.

DAMM, U.; CANNON, P.F.; WOUDENBERG, J.H.C.; CROUS, P.W. The Colletotrichum acutatum species complex. Studies in Mycology, v.73, p.37-113, 2012. DOI: 10.3114/sim0010.

DANQUAH, J.A.; OFORI, K. Variation and correlation among agronomic traits in 10 accessions of garden egg plant (Solanum gilo Raddi) in Ghana. International Journal of Science and Nature, v.3, p.373-379, 2012.

DELIOPOULUS, T.; KETTLEWELL, P.S.; HARE, M.C. Fungal disease suppression by inorganic salts: a review. Crop Protection, v.29, p.1059-1075, 2010. DOI: 10.1016/j.cropro.2010.05.011.

HELRICH, K. Official methods of analysis of the Association of Official Analytical Chemists. 15 ${ }^{\text {th }}$ ed. Washington: AOAC, 1990. v.1, 684p.
JOAQUIM, A.C.V.; FRONZA, C.; FAGUNDES, E.; SANTOS, G.C.P. dos; CARUSI, J.; PINTO, E.R.M.; MORINI, M.C.Z.; ALMEIDA, L. Jiló tipo rami. Revista Eletrônica de Educação e Tecnologia do SENAI-SP, v.4, p.1-56, 2010. Disponível em: $\quad<$ http://revistaeletronica.sp.senai.br/index.php/seer/article/ viewFile/160/99>. Acesso em: 2 out. 2014.

KAR, M.; MISHRA, D. Catalase, peroxidase and polyphenoloxidase activities during rice leaf senescence. Plant Physiology, v.57, p.315-319, 1976. DOI: 10.1104/pp.57.2.315.

KOSHIBA, T. Cytosolic ascorbate peroxidase in seedlings and leaves of maize (Zea mays). Plant and Cell Physiology, v.34, p.713-721, 1993.

LATIFA, A.; IDRISS, T.; HASSAN, B.; AMINE, S.M.; HASSANE, B.E.; ABDELLAH, A.B.A. Effects of organic acids and salts on the development of Penicillium italicum: the causal agent of citrus blue mold. Plant Pathology Journal, v.10, p.99-107, 2011. DOI: 10.3923/ppj.2011.

LOBATO, M.C.; MACHINANDIARENA, M.F.; TAMBASCIO, C.; DOSIO, G.A.A.; CALDIZ, D.O.; DALEO, G.R.; ANDREU, A.B.; OLIVIERI, F.P. Effect of foliar applications of phosphite on post-harvest potato tubers. European Journal of Plant Pathology, v.130, p.155-163, 2011. DOI: 10.1007/s10658-011-9741-2.

MILLS, A.A.S.; PLATT, H.W.; HURTA, R.A.R. Effect of salt compounds on mycelial growth, sporulation and spore germination of various potato pathogens. Postharvest Biology and Technology, v.34, p.341-350, 2004. DOI: 10.1016/j.postharvbio.2004.05.022.

MANGAN, F.X.; MENDONÇA, R.U. de; MOREIRA, M.; NUNES, S. del V.; FINGER, F.L.; BARROS, Z. de J.; GALVÃO, H.; ALMEIDA, G.C.; SILVA, R.A.N.; ANDERSON, M.D. Production and marketing of vegetables for the ethnic markets in the United States. Horticultura Brasileira, v.26, p.6-14, 2008. DOI: 10.1590/S0102-05362008000100002.

NERES, C.R.L.; VIEIRA, G.; DINIZ, E.R.; MOTA, W.F. da; PUIATTI, M. Conservação do jiló em função da temperatura de armazenamento e do filme de polietileno de baixa densidade. Bragantia, v.63, p.431-438, 2004. DOI: 10.1590/S000687052004000300013.

OGOSHI, C.; ABREU, M.S. de; SILVA, B.M. da; SANTOS NETO, H.; RIBEIRO JÚNIOR, P.M.; RESENDE, M.L.V. de. Potassium phosphite: a promising product in the management of diseases caused by Colletotrichum gloeosporioides in coffee plants. Bioscience Journal, v.29, p.1558-1565, 2013.

OLIVIERI, F.P.; FELDMAN, M.L.; MACHINANDIARENA, M.F.; LOBATO, M.C.; CALDIZ, D.O.; DALEO, G.R.; ANDREU, A.B. Phosphite applications induce molecular modifications in potato tuber periderm and cortex that enhance resistance to pathogens. Crop Protection, v.32, p.1-6, 2012. DOI: 10.1016/j. cropro.2011.08.025.

PEREIRA, A.V. da S.; MARTINS, R.B.; MICHEREFF, S.J.; SILVA, M.B.; CÂMARA, M.P.S. Sensitivity of Lasiodiplodia theobromae from Brazilian papaya orchards to MBC and DMI fungicides. European Journal of Plant Pathology, v.132, p.489-498, 2012. DOI: 10.1007/s10658-011-9891-2. 
PEREIRA, R.B.; PINHEIRO, J.B.; ANDERSON, J.; REIS, A. Doenças e pragas do jiloeiro. Brasília: Embrapa Hortaliças, 2012. 13p. (Embrapa Hortaliças. Circular técnica, 106).

REIS, A.; BOITEUX, L.S.; HENZ, G.P. Antracnose em hortaliças da família Solanacea. Brasília: Embrapa Hortaliças, 2009. 9p. (Embrapa Hortaliças. Comunicado técnico, 79).

SILVA, F. de A.S. e; AZEVEDO, C.A.V. de. Principal components analysis in the software assistat-statistical assistance. In: WORLD CONGRESS ON COMPUTERS IN AGRICULTURE, 7., 2009, Reno. Proceedings. St. Joseph: American Society of Agricultural and Biological Engineers, 2009. Available at: $<$ http://www.assistat. com/indexp.html>. Accessed on: 2 Oct. 2014.

SHANER, G.; FINNEY, R.E. The effect of nitrogen fertilization on the expression of slow-mildewing resistance in Knox wheat. Phytopathology, v.67, p.1051-1056, 1977. DOI: 10.1094/ Phyto-67-1051.
SHI, X.-Q.; LI, B.-Q.; QIN, G.-Z.; TIAN, S.-P. Antifungal activity and possible mode of action of borate against Colletotrichum gloeosporioides on mango. Plant Disease, v.95, p.63-69, 2011. DOI: 10.1094/ PDIS-06-10-0437.

STELLA, P.F.; STEFFENS, C.A.; AMARANTE, C.V.T. do; MARTIN, M.S. Maturação, amadurecimento de frutos e controle de podridões de Penicillium spp. em maçãs 'Fuji' com a aplicação pré-colheita de indutores de resistência. Revista de Ciências Agroveterinárias, v.12, p.31-38, 2013.

TABELA brasileira de composição de alimentos - TACO. 4.ed. rev. e ampl. Campinas: Nepa/Unicamp, 2011. 161p.

TOZZE JÚNIOR, H.J.; MELLO, M.B.A.; MASSOLA JÚNIOR, N.S. Caracterização morfológica e fisiológica de isolados de Colletotrichum sp. causadores de antracnose em solanáceas. Summa Phytopathologica, v.32, p.71-79, 2006. DOI: 10.1590/ S0100-54052006000100011.

Recebido em 27 de abril de 2014 e aprovado em 4 de novembro de 2014 